\title{
A Review on the Adoption of Agile Methods in the Technology Development for Smart Cities
}

\author{
Vanessa França Rocha ${ }^{1}$, Lucas de Souza Alves ${ }^{1}$, Valdemar Vicente \\ Graciano Neto $^{1}$, Mohamad Kassab ${ }^{2}$ \\ ${ }^{1}$ Instituto de Informática - Universidade Federal de Goiás (UFG) \\ Goiânia - GO - Brazil \\ ${ }^{2}$ The Pennsylvania State University Malvern, PA, U.S.A \\ \{vanessarocha, lucassouza, valdemarneto\}@inf.ufg.br, muk36@psu.edu
}

\begin{abstract}
Smart cities are a standard concept of automated and sustainable cities that adopt technology to increase efficiency in communication, management and globalization of information. Despite the success of the concept, there is an emerging need to develop and deploy software and software-based systems for these cities. Thus, agile methodologies can play an important role, once they are broadly adopted in systems development lifecycle. This paper presents the result of a systematic mapping conducted on agile processes to develop software for smart cities. A systematic mapping identified 246 studies, from which 10 were selected for analysis and presentation of the results obtained.
\end{abstract}

\section{Introduction and Background}

According to ONU, more than $54 \%$ of the world's population lives in urban areas [United Nations 2014]. This number can reach 2/3 of the world's population by 2050. Consequently, new technologies that contribute to the urbanization process must be adopted to ensure a better quality of life for the population, optimizing the resources management and infrastructure [Pla-Castells et al. 2015]. City governments have adopted programs known as Smart Cities, which adopt technology to support communication and information management. The smart city concept comprises the intensive adoption of technology mostly based on internet-of-things (IoT) and software solutions to optimize city operations and services through connecting citizens and providing comfort and security [Mardacany et al. 2018, IEEE 2018]. In parallel, The technologies and software developed to be used in those cities are becoming increasingly complex, which demand processes to guarantee more efficiency while maximizing quality but still considering budget restrictions and a fast time-to-market. Millionaire investments and time-to-market demand agile delivery in the deployment of those models.

Agile methodologies (AM) such as Scrum, XP and Lean are known prescriptive software development models that have potential to contribute to the development of those technologies (particularly regarding software solutions). AM drive team management processes that contribute to the quality of the final product, accelerating delivery, and reducing the impact of changes that are actually frequent and necessary in those projects given their innovation and novelty nature [Savoine et al. 2016]. Therefore, with world-wide seeking for smart cities adoption, agile models are suitable alternatives for their implementation, since AM (i) prescribe planned and efficient mechanisms to ensure a positive impact on time and budget, (ii) make it more productive for smart cities 
stakeholders and users, (iii) give a faster feedback for novel technologies, (iv) reduce impact of changes and (v) increase productivity [Kent 2001]. AM cope with smart cities requirements, particularly with agility, since they also promote a de-bureaucratization of traditional software development processes [Savoine et al. 2016]. The agile manifesto, published in 2001, externalized the practices that should be followed to achieve agility in software engineering [Kent 2001]. The manifest comprises 12 basic principles, which are: Customer satisfaction is a priority, Requirements changes are constant and accepted, Frequent delivery of executable software, Developers work together, Projects should be carried out by motivated individuals, Face-to-face conversation, Software running, Sustainable development, Technical excellence and good design, Simplicity, Selforganized teams and Inspection and adaptation. Its philosophy is to provide many versions of the software work in short iterations and update the software according to customer feedback [Malik and Siew 2009]. There are about 20 different AM, as described by [Abrahamsson et al. 2003]. AM like as Scrum, Extreme Programming (XP), Lean, Feature Driven Development (FDD), Test-Driven Development (TDD) and Dynamic System Development Model (DSDM) follow agile values and principles with some key practices and have been chosen for demonstrating a range of general practices and specifications [Anwer et al. 2017].

Considering the aforementioned context, the main purpose of this paper is to present the results of a systematic mapping of the literature (SML) about the adoption of AM in the development of software technologies for smart cities. The remainder this paper is organized as follows: Section 2 outlines the planning and conduction of this SM. Section 3 presents the obtained results and discussion on the results. Section 4 concludes the paper with final remarks and pointing out future work.

\section{Systematic Mapping Of Agile Methods For Smart Cities}

Systematic Mapping Protocol. The SML on AM for smart cities was carried out from August 20nd, 2018 to December 7th, 2018. We adopted the process proposed by [Petersen et al. 2015]. The process involved four researchers. Phase 1 consisted of planning, defining the protocol and the research questions that guided the selection of the primary studies. Phase 2 consisted of selecting the studies from the protocol and defined questions. Then phase 3 involved the initial selection of the studies and eliminating duplicate publications. In phase 4, the inclusion and exclusion criteria were applied, considering only the title and study summary reading. Finally, Phase 5 concluded the process by a full reading of the studies, data extraction, analyses, synthesis and results registration.

The PICOC method proposed by [Petticrew and Roberts 2006] assisted in the elaboration of the research questions and construction of the search string. The population $(\mathrm{P})$ was defined as the domain of smart cities and its common synonym was used to maximize the recovery of studies that were also relevant but that eventually used related terms. The intervention refers to the type of technique or method to be applied to the population that is aimed to have its impact investigate. Hence, intervention (I) was defined based on the terms that denote agile methodologies, their synonyms, and most known instances (Agile Methodologies, Scrum, Test Driven Development, Feature-Driven Development, Extreme Programming, Lean, Hybrid-Agile Methodology). Comparison, Result and Context were not considered for mapping purposes, as recommended by the established guidelines [Petersen et al. 2015]. 
Research Questions. The research questions (RQ) were established as shown in Table 1.

Table 1. Research Questions and Rationale.

\begin{tabular}{|l|l|}
\hline $\boldsymbol{R Q}$ & Rationale \\
\hline $\begin{array}{l}\text { RQ1: Which agile methods, } \\
\text { processes or frameworks are }\end{array}$ & $\begin{array}{l}\text { Several methodologies can meet and require different specific needs in } \\
\text { technologies or smart city management. The answer to this RQ can } \\
\text { used in the development of } \\
\text { technologies for Smart Cities? }\end{array}$ \\
\hline $\begin{array}{l}\text { RQ2: When and where were } \\
\text { cities and which ones have been broadly used. }\end{array}$ & $\begin{array}{l}\text { The response to this RQ informs about the growth of research in the } \\
\text { area over the years, in addition to the publication vehicles where the } \\
\text { publications are being published. }\end{array}$ \\
\hline $\begin{array}{l}\text { RQ3: What results are ob- } \\
\text { tained by implementing agile } \\
\text { methods, processes, or frame- } \\
\text { works in Smart Cities? }\end{array}$ & $\begin{array}{l}\text { We intend to realize the specific advantages achieved by using AM, } \\
\text { processes or frameworks in smart cities, helping to guide and identify } \\
\text { limitations and gaps that should be addressed by forthcoming research. }\end{array}$ \\
\hline
\end{tabular}

Inclusion and Exclusion Criteria. The selection strategy should be elaborated using inclusion and exclusion criteria (IC and EC) to evaluate the quality of the selected studies [Kitchenham and Charters 2007]. IC were defined to include relevant studies; EC were proposed to exclude studies that do not contribute to answering the research questions; and Quality Questions (QQ) were used to evaluate the quality of the studies returned during the research. IC, EC and QQ are presented in Table 2.

Table 2. Inclusion, Exclusion Criteria and Quality Questions

\begin{tabular}{|c|l|}
\hline Inclusion & (IC1): The primary study proposes the use of methodologies, processes or agile \\
frameworks in some cases, software or templates on smart cities; \\
(IC2): The study explicitly reports agile methods, structures or processes in intelligent \\
cities.
\end{tabular}

Conduction. The search strategy adopted for this SML was automatic search in some bibliographic bases and search engines to obtain the primary studies through the string. For the formulation of the string search, the main terms used in the research questions were identified. PICOC, synonyms, variations, and terms related to each keyword were identified. The OR operator was used to allow the use of synonyms and related terms, and the conjunction AND joined Population and Intervention in the string to maximize the return of relevant studies on agile methods in smart cities. 
A pilot test was performed to calibrate the search string. We realized a large number of studies was retrieved because many authors used the term 'agile' to denote an increase in the mobility in a city, which was not our research interest. Then, we restricted the search to title, abstract, and keywords, and also included the terms "HAM" and "Hybrid Agile Methodology" to the search string, as it has emerged during the pilot study and denotes the use of two different agile methodologies or the combination of agile methods with other non-agile techniques. Thus, after calibration and refinement, the string achieved the following form.

\begin{tabular}{|c|}
\hline mart Cit*" OR "Smart-Cit*" OR "Digital Cit*") AND ("Agile" OR "Agile Met \\
\hline
\end{tabular}

The bibliographic bases used for this research were the ACM and the IEEE, because they contain a collection of relevant studies for the area. To ensure that the selected set of studies is complete and relevant studies are not lacking, we extended the search to Google Scholar and Engineering Village since it involved more indexed studies that could contribute significantly to this mapping. Next section presents the results.

\section{Results}

Our research returned 246 studies of the chosen bases. 33 duplicated studies were eliminated. Thus, 213 studies followed to the selection phase. After applying the inclusion and exclusion criteria in the study summary and title, 16 studies, about $7.51 \%$ of the total, were selected for full reading. The ACM database returned three studies of which only one was included, the IEEE bibliographic source returned 29 studies, where six of them were included, the Google Scholar search engine brought 11 studies and only two were included and the search engine Research Engineering Village was the one that most returned studies with a total of 202, but only one was included. Thus, the total of 10 studies were included.

When reading and analyzing the articles considering the research questions, the selected articles were submitted to a quality assessment checklist and the information was extracted and placed on an extraction form. If the decision on whether to include or exclude a study was unclear, the discussions were conducted among the four reviewers. Table 3 summarizes our results by presenting the ten selected studies as included and reviewed, as the six previously selected studies have been excluded because they use only the agile term to define agility without addressing agile processes or methods in some context in smart cities. It was also considered the focus of the research, that allows to identify the studies related to each specific field. Details about the analyzed studies and their classification can be found externally ${ }^{1}$.

\subsection{Research Questions}

RQ1: What agile methods, processes, or frameworks are used in Smart Cities? The selected studies were listed and defined by their ID, as follows: S1 [Karouw and Wowor 2013], S2 [Lee and DK 2017], S3 [Lom et al. 2016],

\footnotetext{
${ }^{1}$ https://sites.google.com/view/smlagilemethodssmartcities.
} 
Table 3. List of included Primary Studies.

\begin{tabular}{|c|c|c|c|c|c|c|}
\hline $\begin{array}{l}\text { Study } \\
\text { ID }\end{array}$ & Titles & Authors & IC & $\begin{array}{l}\text { Focus used } \\
\text { Agile Method }\end{array}$ & Year & $\begin{array}{l}\text { Authors } \\
\text { Nationalities }\end{array}$ \\
\hline S1 & $\begin{array}{l}\text { E-Rakorev and Towards governance planning, } \\
\text { monitoring and evaluation of urban development for } \\
\text { Manado Smart City. }\end{array}$ & $\begin{array}{l}\text { Karouw, S. } \\
\quad \text { et al. }\end{array}$ & $\begin{array}{l}\text { IC1, } \\
\text { IC2 }\end{array}$ & $\begin{array}{l}\text { Tools and } \\
\text { technologies }\end{array}$ & 2013 & Indonesia \\
\hline $\mathrm{S} 2$ & $\begin{array}{l}\text { An entrepreneurial narrative media-model framework } \\
\text { for knowledge building and open co-design for smart } \\
\text { cities }\end{array}$ & Lee et. al. & $\begin{array}{l}\text { IC1 } \\
\text { IC2 }\end{array}$ & $\begin{array}{l}\text { Process } \\
\text { management }\end{array}$ & 2017 & Malaysia \\
\hline S3 & Hybrid-Agile Approach in Smart Cities Procurement & $\begin{array}{l}\text { Lom, M. et } \\
\quad \text { al. }\end{array}$ & $\begin{array}{l}\text { IC1 } \\
\text { IC2 }\end{array}$ & $\begin{array}{l}\text { Management / } \\
\text { organizational }\end{array}$ & 2016 & $\begin{array}{l}\text { Czech } \\
\text { Republic }\end{array}$ \\
\hline $\mathrm{S} 4$ & $\begin{array}{l}\text { Smart as a Key Component of the Sustainable City } \\
\text { Development }\end{array}$ & $\begin{array}{l}\text { Zelinka, T. } \\
\text { et al. }\end{array}$ & $\begin{array}{l}\text { IC1 } \\
\text { IC2 }\end{array}$ & $\begin{array}{l}\text { Management / } \\
\text { organizational }\end{array}$ & 2016 & $\begin{array}{l}\text { Czech } \\
\text { Republic }\end{array}$ \\
\hline S5 & $\begin{array}{l}\text { Involving citizens in smart city projects: Systems } \\
\text { engineering meets participation. }\end{array}$ & $\begin{array}{l}\text { Vácha, T. et } \\
\text { al. }\end{array}$ & $\begin{array}{l}\text { IC1 } \\
\text { IC2 }\end{array}$ & $\begin{array}{l}\text { Process } \\
\text { management }\end{array}$ & 2016 & $\begin{array}{l}\text { Czech } \\
\text { Republic }\end{array}$ \\
\hline S6 & $\begin{array}{l}\text { Hackathons, Semester Athens, and Summerathons } \\
\text { vehicles to Develop Smart City local talent that through } \\
\text { their innovations promote synergy between Industry, } \\
\text { Academia, Government and Citizens. }\end{array}$ & $\begin{array}{l}\text { Avalos, M. } \\
\quad \text { et al. }\end{array}$ & $\begin{array}{l}\text { IC1, } \\
\text { IC2 }\end{array}$ & $\begin{array}{l}\text { Process } \\
\text { management }\end{array}$ & 2017 & Mexico \\
\hline S7 & $\begin{array}{l}\text { The concept selection of lean software and system } \\
\text { engineering tools for smart cities. }\end{array}$ & $\begin{array}{l}\text { Redmond, } \\
\text { M. et. al. }\end{array}$ & $\begin{array}{l}\text { IC1, } \\
\text { IC2 }\end{array}$ & $\begin{array}{l}\text { Management / } \\
\text { organizational }\end{array}$ & 2017 & Irland France \\
\hline S8 & $\begin{array}{l}\text { Agile Environmental Monitoring Exploits Rapid } \\
\text { Prototyping and In Situ Adaptation. }\end{array}$ & $\begin{array}{l}\text { Kishino, Y. } \\
\text { et al. }\end{array}$ & IC1 & $\begin{array}{c}\text { Software } \\
\text { development }\end{array}$ & 2017 & Japan \\
\hline S9 & CitySense: blockchain-oriented smart cities. & $\begin{array}{l}\text { Ibba, S., et } \\
\quad \text { al. }\end{array}$ & $\begin{array}{l}\text { IC1 } \\
\text { IC2 }\end{array}$ & $\begin{array}{c}\text { Process } \\
\text { management }\end{array}$ & 2017 & Italy \\
\hline $\mathrm{S} 10$ & $\begin{array}{l}\text { An agile framework for modeling smart city business } \\
\text { ecosystems. }\end{array}$ & $\begin{array}{l}\text { Faber, A. et } \\
\quad \text { al. }\end{array}$ & $\begin{array}{l}\text { IC1, } \\
\text { IC2 }\end{array}$ & $\begin{array}{l}\text { Management / } \\
\text { organizational }\end{array}$ & 2018 & Germany \\
\hline
\end{tabular}

S4 [Zelinka et al. 2016], S5 [Vácha et al. 2016], S6 [Avalos et al. 2017], S7 [Redmond and A. 2017], S8 [Kishino et al. 2017], S9 [Ibba et al. 2017] and S10 [Faber et al. 2018].

Ten studies talk about the use of agile methods, processes or frameworks used in the context of smart cities. Six of them used the scrum framework (S3, S4, S5, S6, S7, S9, S10), one of them Lean methodology (S2, S7), three of them used the hybrid methodologies known as HAM (S3, S4, S5) and the other studies (S1, S2, S7, S10) used a combination of some practices of different agile methodologies or management processes. From these selected studies four use more than one methodology to apply, develop and manage software in smart cities or are used for planning and managing processes ( S3, S4, S5, S7). Table 4 lists the distribution of agile methods in the included studies.

$\mathrm{S} 1$ demonstrates the process of analysis and design of information system eRakorev for BAPPEDA and how to develop e-Rakorev application using the agile, workoriented approach of Pusilkom Agile Unified Process (PAUS). Study S2 involves the students of a group of information systems analysis course, in which agile methodologies were used in the context of the development of web products. The objective of the study was to create a deep knowledge about smart cities, agile methodologies and design thinking to discuss the possibility of implantation of some technologies in Malaysia through the studies carried out by the students and the knowledge acquired by them. 
Table 4. List of by Agile Methods Reported in Included Studies.

\begin{tabular}{|c|c|c|c|c|}
\hline Ref. & Scrum & Lean & HAM & Others \\
\hline S1 & & & & $\mathrm{X}$ \\
\hline S2 & & & & $\mathrm{X}$ \\
\hline S3 & $\mathrm{X}$ & & $\mathrm{X}$ & $\mathrm{X}$ \\
\hline S4 & $\mathrm{X}$ & & $\mathrm{X}$ & \\
\hline S5 & $\mathrm{X}$ & & & \\
\hline S6 & $\mathrm{X}$ & & & $\mathrm{X}$ \\
\hline S7 & $\mathrm{X}$ & $\mathrm{X}$ & & \\
\hline S8 & & & & $\mathrm{X}$ \\
\hline S9 & $\mathrm{X}$ & & & \\
\hline S10 & & & & \\
\hline
\end{tabular}

The S3 and S4 studies use HAM based on agile development principles and the scrum framework in the development of smart cities. Authors report the realization of cooperation and communication between the developer, the client and other stakeholders as the main advantage obtained by the use of agile methods in the development of smart cities during the conduction of the project. S5 target to importance of citizen participation in different phases of the Smart City project and proposes how the Hybrid-Agile methodology (HAM) can be used to involve citizens in the different phases of project implementation, while S7 discusses the comparison of development methodologies agile software, Kanban vs. Scrum, tracking techniques and also addresses the difference between testing Smart City software products using the Vee model and Agile.

The S6 study uses agile methodologies to assist in hosting themed hackathons in smart cities, and an alternative to empower and engage citizens to be aware of how their active participation can positively affect the quality of life in their cities. S7 and S8 use agile methodologies to develop applications for monitoring and evaluation of urban and environmental development. S9 notes that smart cities are connected systems that produce an enormous amount of data that must be available and shared for all. They propose solving the problem of storing and managing sensor data using block chain technology, and to develop the software have opted to apply the scrum.

The study S10 shows how to build an analytical system in the context of a smart city and mobility business ecosystem. For this, the authors use an agile approach to collaboratively manage and adapt business ecosystem models.

RQ2: When and where were the studies published? Figure 1 shows the years and respective number of published studies that were included: 2013 (one study), 2016 (three studies), 2017 (five studies) and 2018 (one study). Authors have published in conferences and journals. Only one of the authors appeared more than once in our results, with two articles published in the same year. Figure 2 shows the distribution of the types of primary studies published. The primary studies were published as conference paper (six studies), journal paper (two studies), workshop publications and symposiums paper (one study each one). These data demonstrate that although the investigation topic is recent and has little research, journals are accepting as a relevant field of research.

RQ3: What results are obtained by implementing agile methods, processes or frameworks in Smart Cities? Some results and advantages in the use of the methods are presented, such as increased project acceptance (S5), fast delivery of versions (S6, S8), 


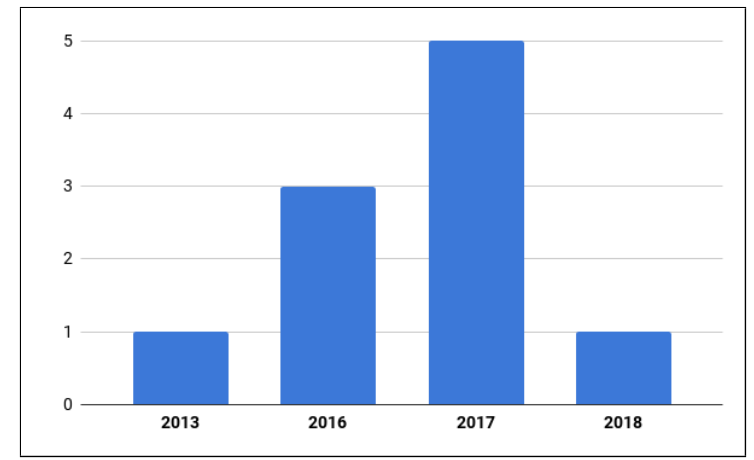

Figure 1. Number of studies published over the years.

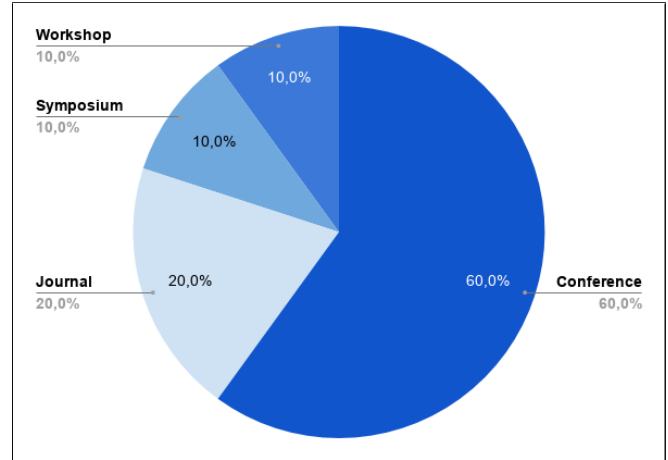

Figure 2. Distribution of studies by publication type.

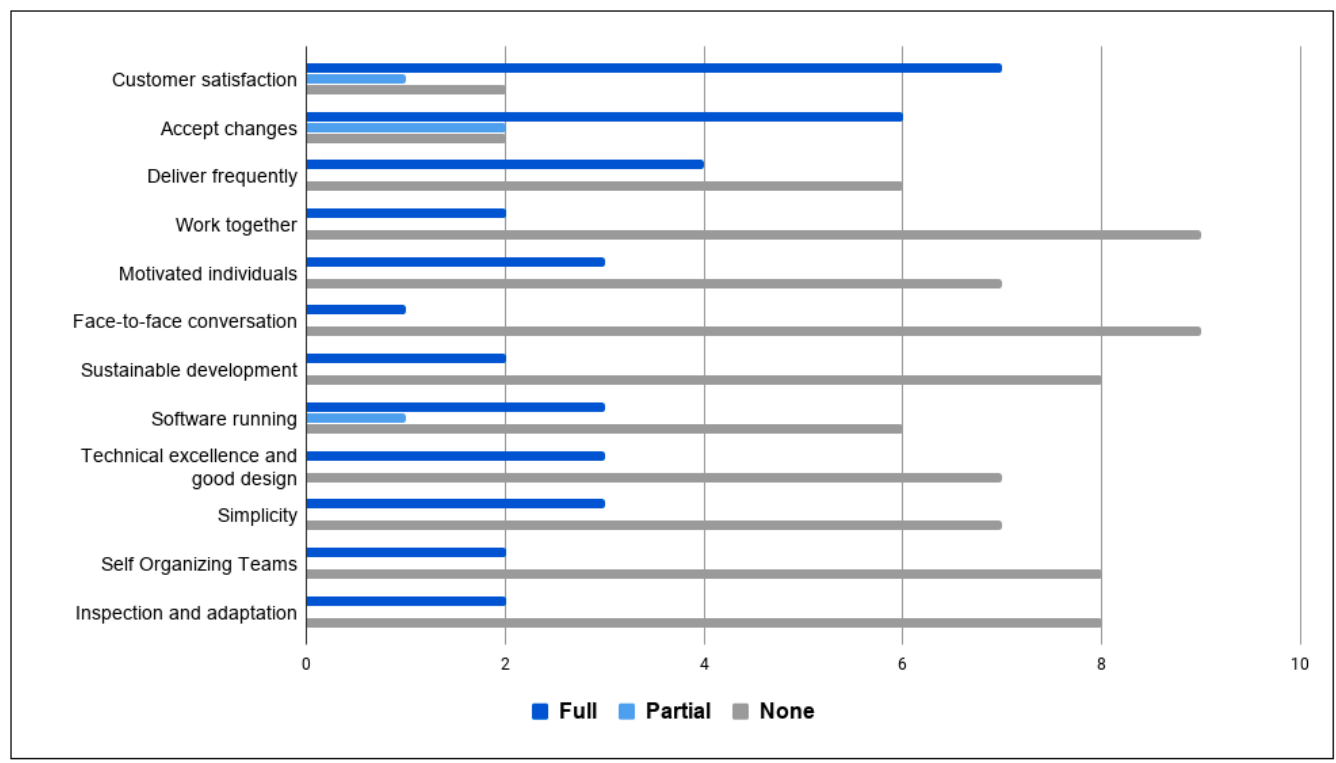

Figure 3. Overall usage of Agile Practices

Table 5. Quality questions answers

\begin{tabular}{|l|l|l|}
\hline Quality Question & Yes & No \\
\hline QQ1 & 9 & 1 \\
\hline QQ2 & 9 & 1 \\
\hline QQ3 & 1 & 9 \\
\hline QQ4 & 3 & 7 \\
\hline
\end{tabular}

feedback and greater participation of clients during the project (S3, S4, S5, S9) were identified as important attributes in the results obtained during the projects developed in the studies. S7 further state that a hybrid model of different techniques increases transparency, mitigates risk early and quality for software development, contributing to the customer requirements of a team that is self-organized and manageable.

Figure 3 shows relevance of the studies (total, partial or none) in relation to the research question. When analyzing the significance of the studies, for example, it can be verified which studies are directly related to the development of software or project 
management using agile practices for smart cities. From the selected studies, seven of them addressed some type of practice or agile methodology principles during the entire smart cities project. The agile practices most used are customer satisfaction (six out of ten studies), acceptance for changes (five studies), software running and technical excellence and good design (three studies each).

Studies Quality. The results of the quality assessment are presented in Table 5. Quality issues QQ1 and QQ2 obtained answers mostly yes, regarding the justifications of the study and use of agile methodologies, only one study had vague statement. In regard to QQ3, only one study reported problems in implementation, the others did not address. The QQ4 had only three studies that did not answer the question with yes, i.e., there were no studies related to the current work reported by the authors.

Threats to Validity. The results presented by this SML may have been affected due to some factors, such as study distribution, partial coverage in the bibliographic bases used and the terms used for the search string. We identified some major threats regarding the selection and inclusion of the studies and sought to minimize them through mitigation actions.

The first threat to validity is regarding the relevant studies returned, there is the possibility of the existence of relevant documents that we can not identify by our research. We searched the most popular bibliographic databases and could return a larger number of relevant studies of the area to which several surveys are indexed, avoided delimiting dates to extract the maximum of relevant studies, however, studies may have been lost as to the number of bases (used only four).

One of the main challenges in planning SMLs is the construction of the electronic search string. In the search string, we mapped the most used terms in smart cities and agile methodologies, so there was no complete coverage of the agile methodologies (about 20) that currently exist. In addition, errors may have occurred in the protocol definition and the search string did not contain all relevant keywords, causing the loss of some valuable studies. Only two researchers performed the parallel extraction stage. We minimized this bias where there was disagreement as to the results of both researchers causing the other researchers to revise to agree on the work to be included.

Finally, another threat to this mapping was the use of the term "agile" in the search string in the studies, thus returning irrelevant studies to the results. The level of depth of the use of agile practices by the authors in their research was also a threat using only some practices or approach, and interpretation by the reviewers is necessary.

Discussion. The studies are published involving the agile methodologies in the context of smart cities. Both for the development of the software to be used in this environment, and in the management of internal processes, proven that six of the ten studies use the scrum methodology, which has a greater focus on management and customer participation in the project. We analyzed from which countries the studies were carried out by the authors, and we observed that three articles were addressed in the Czech Republic and the others in different countries, not having a strong concentration in a certain region. The main concern of the projects is the participation of the citizen in the process. Citizens have an important role in smart cities, since they will be the main users of the system. Then, active involvement with the city through their participation and interaction in decision making in 
political life, agile methodologies would contribute to this process, where citizens present problems, participate in the development and ensure that what is being developed is what will actually be delivered.

Described on agile manifesto, the stakeholder's participation is essential and agile methodologies like scrum has this defined on your process, how in smart cities the main stakeholder is the citizens, some new technologies can approach they with more facilities to append and present an approach nearby to reality. Many software projects are unable to fully utilize agile methodologies practices and incorporate other methods, agile or not to complements and fit the initially anticipated needs, so four of these studies use more than one approach in the process, this happens by many reasons, a new approach, a project create initially without a defined structure or simply by project manager decision. Most companies adapt these methods due to several problems, such as the complexity encountered during the introduction or the shift to agile development [Salo and Abrahamsson 2008]. This leads to many adaptations of agile methods that appear in the literature [Diebold et al. 2013].

\section{Final Remarks}

This paper presented an overview of a mapping on the adoption of agile methodologies (AM) in the development of technologies for smart cities. Ten out of 246 studies were selected, reviewed, and included. From the obtained results, we highlight the following: (i) five studies use agile methodologies to management of acquisition processes and implementation of contracts and biddings on Smart Cities, (ii) the other five studies has applied AM to development software projects. Scrum was identified as one of the main methods used by the projects. The main reason is that the stakeholder participation during the different phases of the Smart City project is fostered by this methodology. Some studies have combined more than one type of AM, developing their own model or adapting. This topic is still ascending, showing opportunities and gaps to be investigated. Future work includes extending this mapping to obtain more consolidated results and define a possible framework and model to support AM adaptation for specific contexts of development.

\section{References}

Abrahamsson, P., Warsta, J., Siponen, M., and Ronkainen, J. (2003). New directions on agile methods: a comparative analysis. In 25th ICSE, pages 244-254, Oregon. IEEE.

Anwer, F., Aftab, S., Waheed, U., and Muhammad, S. (2017). Agile software development models tdd, fdd, dsdm, and crystal methods: A survey. International Journal of Multidisciplinary Sciences and Engineering, VOL. 8, NO. 2.

Avalos, M., Larios, V., Salazar, P., and Maciel, R. (2017). Hackathons, semesterathons, and summerathons vehicles to develop smart city local talent through their innovations promote synergy between industry, academia, government and citizens. International Smart Cities Conference.

Diebold, P., Lampasona, C., and Taibi, D. (2013). Moonlighting scrum: An agile method for distributed teams with part-time developers working during nonoverlapping hours. pages 318323. 8th ICSEA. IARIA XPS Press, Wilmington.

Faber, A., Hernandez-Mendez, A., Rehm, S., and Matthes, F. (2018). An agile framework for modeling smart city business ecosystems. ICEIS 2018 - Proceedings of the 20th International Conference on Enterprise Information Systems. 
Ibba, S., Pinna, A., His, M., and Eros, F. (2017). Citysense: blockchain-oriented smart cities. Proceedings of the XP2017 Scientific Workshops.

IEEE (Retrieved November 2018). About smart cities. Accessible online: http://smartcities.ieee.org/about.

Karouw, S. and Wowor, H. (2013). e-rakorev: Towards governance planning, monitoring and evaluation of urban development for manado smartcity. International Conference on Advanced Computer Science and Information Systems (ICACSIS).

Kent, B. (2001). Principles behind the agile manifest. Agile Alliance.

Kishino, Y., Yanagisawa, Y., Shirai, Y., Mizutani, S., Suyama, T., and Naya, F. (2017). Agile environmental monitoring exploits rapid prototyping and in situ adaptation. pages 61-71. IEEE Pervasive Computing, vol. 16, no. 2.

Kitchenham, A. and Charters, S. (2007). Guidelines for performing systematic literature reviews in software engineering. Technical Report, EBSE-2007-01.

Lee, C. and DK, W. (2017). An entrepreneurial narrative media-model framework for knowledge building and open co-design for smart cities. Computing Conference.

Lom, M., Prlbyl, O., and Zelinka, T. (2016). Hybrid agile approach in smart cities procurement. Conference: 20th World Multi-Conference on Systemics, Cybernetics and Informatics.

Malik, H. and Siew, H. (2009). Review of agile methodologies in software development. International Journal of Research and Reviews in Applied Sciences.

Mardacany, E., Miet, C., and Frgs, A. (2018). Smart cities in india: Features, policies, current status and challenges. Technologies for Smart-City Energy Security and Power.

Petersen, K., Vakkalanka, S., and Kuzniarz, L. (2015). Guidelines for conducting systematic mapping studies in software engineering: An update. Information and Software Technology.

Petticrew, M. and Roberts, H. (2006). Systematic reviews in the social sciences: A practical guide. Oxford: Blackwell.

Pla-Castells, R., Martinez-Durá, J., Samper-Zapater, J., and Cirilo-Gimeno, R. (2015). Use of ict in smart cities. a pratictal case applied to traffic management in the city of valencia. Smart Cities Simposium Prague.

Redmond, A. and A., Z. (2017). The concept selection of lean software and system engineering tools for smart cities. International Conference on Engineering, Technology and Innovation.

Salo, O. and Abrahamsson, O. (2008). Agile methods in european embedded software development organisations: a survey on the actual use and usefulness of extremme programming and scrum. pages 58-64. IET Software 2, 1.

Savoine, M., Rocha, V., Bezerra, C., Araújo, A., and Matias, J. (2016). A synchronous agile framework proposal combining scrum and tdd. page 350. ICSEA.

United Nations (2014). Department of Economic and Social Affairs Population Division. The World population Situation in 2014: A Concise Report. NY.

Vácha, T., Přibyl, O., M., L., and M., B. (2016). Involving citizens in smart city projects: Systems engineering meets participation. Smart Cities Symposium Prague (SCSP).

Zelinka, T., Prlbyl, O., and Lom, M. (2016). Smart as a key component of the sustainable city development. pages 16-21. Journal on Systemics, Cybernetics and Informatics, vol. 14, no. 5. 